\title{
MORTALITY BURDEN OF NON COMMUNICABLE DISEASE - A RETROSPECTIVE STUDY IN A TERTIARY CARE HOSPITA1L OF BANGLADESH
}

\author{
BINOY KRISHNA TARAFDER ${ }^{1}$, AHMED MANADIR HOSSAIN ${ }^{1}$, KARZAN DEY SARKER ${ }^{2}$, PALASH KUMAR \\ PODDER ${ }^{3}$, MUHAMMAD NURUL ISLAM ${ }^{2}$,MD. MOSTAFIZURRAHMAN ${ }^{3}$, SURANJIT KUMAR SAHA ${ }^{4}$, \\ MOHAMMAD TANVIR ISLAM ${ }^{5}$, MOHAMMAD EHASUN UDDIN KHAN ${ }^{6}$
}

\begin{abstract}
:
Pattern of mortality gives a picture of disease burden of a community and helps in evaluation of health care system. A retrospective study was done in medicine wards of a tertiary care hospital in Bangladesh from $1^{\text {st }}$ July 2014 to 30st June 2015 to see the mortality pattern. Data obtained from death and admission registrar. Total 1306 deaths were recorded. Mortality rate was 7\%. Male female ratio was 1.65:1. Average age at death was 56.05 years. Highest 11.3\% death occurred in January, 48.6\% deaths occurred during night shift. Average stay in hospital was 42.1 hours. Non communicable disease causing 87\%, communicable disease causing $8.8 \%$ deaths and $4.2 \%$ were brought dead and undiagnosed. Stroke and IHD caused 54.1\% deaths. Among diagnosed causes, ratio of NCD and CD was 9.9:1.
\end{abstract}

Key words: Mortality, non communicable disease, tertiary care hospital, Bangladesh.

Received: 5 September 2015

Accepted: 3 November 2015

\section{Introduction:}

Pattern of morbidity and mortality is a reflection of disease burden of a community. Though in hospital mortality and death pattern may not represent the actual disease burden in general population, they give insight into the disease causing more fatality and at the same time looks out for any change in the disease patternand mortality in the community over time. ${ }^{1,2}$ So review of mortality pattern is an important exercise and used in evaluation of the health care system of a particular institution as well as the community. This knowledge guides to appropriate health planning and to take necessary steps by the government and international health agencies to reduce mortality by improving health care services. ${ }^{1}$ Many factors affect in hospital mortality. Over many of them, hospital authority and the physicians have no control like age, sex, severity of disease on admission, co-morbidity, social and economic condition of the patient, duration of hospital stay, infrastructure and facilities available in that particular hospital. ${ }^{3}$ Resources, technological development, geographical situation,culture and behavior of a community also varies worldwide. So global disease burden and pattern of mortality vary enormously between countries and also between hospitals. As for example, cardiovascular disease is the leading cause of death in all developed and developing countries now a days but infection is still the major cause of death in sub Saharan Africa. ${ }^{4}$ Still there are some factors that can be modified and mortality can be improved. Studies worldwide estimate that unintentional error in the treatment may occur in every one in ten hospital admitted patients even in the developed countries and up to $50 \%$ of these are preventable.And $3.5 \%$ deaths are judged to be preventable, though wide variation exists in this number. ${ }^{5}$ In spite of all these factors, global deaths due to non communicable disease (NCD) is increasing. In 2012, non communicable diseases were responsible for $68 \%$ of 56 million global deaths and nearly three quarters of NCD deaths occurred in low and middle income countries. Among deaths due to NCD, cardiovascular events caused $46 \%$ deaths. $^{6}$

1. Assistant Professor, Department of Medicine, Faridpur Medical College, Faridpur, Bangladesh.

2. Registrar, Department of Medicine, Faridpur Medical College Hospital, Faridpur, Bangladesh

3. Assistant Registrar, Department of Medicine, Faridpur Medical College Hospital, Faridpur, Bangladesh

4. Medical Officer, Department of Medicine, Faridpur Medical College Hospital, Faridpur, Bangladesh.

5. Assistant Professor, Department of Internal Medicine, Bangabandhu Sheikh Mujib Medical University, Dhaka, Bangladesh

6. Medical Officer, Department of Gastroenterology, Dhaka Medical College, Dhaka, Bangladesh

Correspondence : Dr. Binoy Krishna Tarafder, Assistant Professor, Department of Medicine, Faridpur Medical College, Faridpur, Bangladesh.Tel : +8801815005452, e-mail : binoymmch@yahoo.com

Bangladesh J Medicine 2016; $27: 22-26$ 


\section{Methods:}

This is a retrospective study to see the mortality pattern done in medicine department of Faridpur Medical College Hospital. Data of deceased patients in medicine ward from $1^{\text {st }}$ July, 2014 to $30^{\text {th }}$ June, 2015 was obtained from the death registrar and admission registrar. In case of incomplete data in the registrar, admission record file were sought and complete data was obtained. Faridpur medical college hospital is a tertiary level hospital situated in Faridpur, a district in the southern part of Bangladesh. Patients from this district and also from surrounding districts come here for treatment. Most of these are rural areas. In spite of being a tertiary level hospital, it lacks ICU facilities. Laboratory facilities are also limited from 8 AM to 2:30 PM. We collected data of all deceased patients within this period. Data were analyzed with SPSS.

\section{Results:}

Total 1306 patients died within this study period out of 18765 admitted patients. Among them, 813 male patients died out of 9782 and 493 female patients died out of 8983 . Mortality rate in male is $8.3 \%$ and in female was $5.5 \%$. Overall mortality was $7 \%$. Male female death ratio was $\mathrm{M}: \mathrm{F}=1.65: 1$. Average age was 56.05 years with minimum age 12 years and maximum age 110 years. Among the deceased patients, $1023(78.3 \%)$ were from rural area and $283(21.7 \%)$ were from urban area.

Table-I

Distribution of deaths according to age $(n=1306)$ :

\begin{tabular}{lccr}
\hline Age (years) & Male (\%) & Female (\%) & Total (\%) \\
\hline$<20$ & $30(2.3 \%)$ & $36(2.8 \%)$ & $66(5.1 \%)$ \\
$21-30$ & $43(3.3 \%)$ & $52(4.0 \%)$ & $95(7.3 \%)$ \\
$31-40$ & $51(3.9 \%)$ & $56(4.3 \%)$ & $107(8.2 \%)$ \\
$41-50$ & $132(10.1 \%)$ & $87(6.7 \%)$ & $219(16.8 \%)$ \\
$51-60$ & $187(14.3 \%)$ & $110(8.4 \%)$ & $297(22.7 \%)$ \\
$61-70$ & $208(15.9 \%)$ & $95(7.3 \%)$ & $303(23.2 \%)$ \\
$71-80$ & $113(8.7 \%)$ & $36(2.8 \%)$ & $149(11.4 \%)$ \\
$81-90$ & $40(3.1 \%)$ & $17(1.3 \%)$ & $57(4.4 \%)$ \\
$91-100$ & $7(0.5 \%)$ & $4(0.3 \%)$ & $11(0.8 \%)$ \\
$>100$ & $2(0.2 \%)$ & $0(0.0 \%)$ & $2(0.2 \%)$ \\
\hline Total & $813(62.3 \%)$ & $493(37.7 \%)$ & $1306(100.0 \%)$ \\
\hline
\end{tabular}

Table II

Distribution of deaths according to month ( $n=1306)$ :

\begin{tabular}{lccc}
\hline Month & Male & Female & Total \\
\hline July'14 & $60(4.6 \%)$ & $32(2.5 \%)$ & $92(7.0 \%)$ \\
August'14 & $61(4.7 \%)$ & $30(2.3 \%)$ & $91(7.0 \%)$ \\
September'14 & $46(3.5 \%)$ & $31(2.4 \%)$ & $77(5.9 \%)$ \\
October'14 & $66(5.1 \%)$ & $38(2.9 \%)$ & $104(8.0 \%)$ \\
November'14 & $92(7.0 \%)$ & $39(3.0 \%)$ & $131(10.0 \%)$ \\
December'14 & $82(6.3 \%)$ & $39(3.0 \%)$ & $121(9.3 \%)$ \\
January'15 & $86(6.6 \%)$ & $62(4.7 \%)$ & $148(11.3 \%)$ \\
February'15 & $73(5.6 \%)$ & $38(2.9 \%)$ & $111(8.5 \%)$ \\
March'15 & $72(5.5 \%)$ & $55(4.2 \%)$ & $127(9.7 \%)$ \\
April'15 & $54(4.1 \%)$ & $49(3.8 \%)$ & $103(7.9 \%)$ \\
May'15 & $61(4.7 \%)$ & $44(3.4 \%)$ & $105(8.0 \%)$ \\
June'15 & $60(4.6 \%)$ & $36(2.8 \%)$ & $96(7.4 \%)$ \\
\hline Total & $813(62.3 \%)$ & $493(37.7 \%)$ & $1306(100.0 \%)$ \\
\hline
\end{tabular}

Table-III

Distribution of deaths according to time of death $(n=1306)$

\begin{tabular}{lccc}
\hline Time of death & Male & Female & Total \\
\hline 8:00AM-2:30PM & $223(17.1 \%)$ & $97(7.4 \%)$ & $320(24.5 \%)$ \\
2:31PM-9:00PM & $216(16.5 \%)$ & $135(10.3 \%)$ & $351(26.9 \%)$ \\
9:01PM-7:59AM & $374(28.6 \%)$ & $261(20.0 \%)$ & $635(48.6 \%)$ \\
\hline Total & $813(62.3 \%)$ & $493(37.7 \%)$ & $1306(100.0 \%)$ \\
\hline
\end{tabular}

Table-IV

Distribution of deaths according to duration of hospital stay $(n=1306)$ :

\begin{tabular}{lccc}
\hline $\begin{array}{l}\text { Hospital stay } \\
\text { (hours) }\end{array}$ & Male & Female & Total \\
\hline$<24$ & $483(37.0 \%)$ & $276(21.1 \%)$ & $759(58.1 \%)$ \\
$25-48$ & $135(10.3 \%)$ & $105(8.0 \%)$ & $240(18.4 \%)$ \\
$49-72$ & $62(4.7 \%)$ & $39(3.0 \%)$ & $101(7.7 \%)$ \\
$73-96$ & $38(2.9 \%)$ & $14(1.1 \%)$ & $52(4.0 \%)$ \\
$97-120$ & $35(2.7 \%)$ & $18(1.4 \%)$ & $53(4.1 \%)$ \\
$121-144$ & $13(1.0)$ & $11(0.8 \%)$ & $24(1.8 \%)$ \\
$145-168$ & $11(0.8 \%)$ & $14(1.1 \%)$ & $25(1.9 \%)$ \\
$169-192$ & $9(0.7 \%)$ & $5(0.4 \%)$ & $14(1.1 \%)$ \\
$193-216$ & $5(0.4 \%)$ & $3(0.2 \%)$ & $8(0.6 \%)$ \\
$217-240$ & $10(0.8 \%)$ & $3(0.2 \%)$ & $13(1.0 \%)$ \\
$>241$ & $12(0.9 \%)$ & $5(0.4 \%)$ & $17(1.3 \%)$ \\
\hline Total & $813(62.3 \%)$ & $493(37.7 \%)$ & $1306(100.0 \%)$ \\
\hline
\end{tabular}

Average stay in hospital before death is 42.1 hours with maximum duration of stay was 820 hours. 
Table-V

Distribution of deaths according to cause ( $n=1306)$ :

\begin{tabular}{|c|c|c|c|}
\hline Disease & Male & Female & Total \\
\hline \multicolumn{4}{|l|}{ NON-COMMUNICABLE DISEASE } \\
\hline Stroke & $256(19.6 \%)$ & $181(13.9 \%)$ & $437(33.5 \%)$ \\
\hline Acute coronary syndrome & $178(13.6 \%)$ & $91(7.0 \%)$ & $269(20.6 \%)$ \\
\hline Poisoning, drowning, hanging & $50(3.8 \%)$ & $47(3.6 \%)$ & $97(7.4 \%)$ \\
\hline COPD & $54(4.1 \%)$ & $8(0.6 \%)$ & $62(4.7 \%)$ \\
\hline Heart failure & $29(2.2 \%)$ & $16(1.2 \%)$ & $45(3.4 \%)$ \\
\hline Malignancy & $26(2.0 \%)$ & $16(1.2 \%)$ & $42(3.2 \%)$ \\
\hline Shock & $32(2.5 \%)$ & $6(0.5 \%)$ & $38(2.9 \%)$ \\
\hline Renal failure & $9(0.7 \%)$ & $13(1.0 \%)$ & $22(1.7 \%)$ \\
\hline CLD & $15(1.1 \%)$ & $5(0.4 \%)$ & $20(1.5 \%)$ \\
\hline Fulminant hepatic failure & $14(1.1 \%)$ & $4(0.3 \%)$ & $18(1.4 \%)$ \\
\hline Cardiomyopathy & $6(0.5 \%)$ & $11(0.8 \%)$ & $17(1.3 \%)$ \\
\hline Valvular heart disease & $1(0.1 \%)$ & $7(0.5 \%)$ & $8(0.6 \%)$ \\
\hline Electrolyte imbalance & $4(0.3 \%)$ & $4(0.3 \%)$ & $8(0.6 \%)$ \\
\hline Cardiac arrhythmia & $4(0.3 \%)$ & $3(0.2 \%)$ & $7(0.5 \%)$ \\
\hline Bronchial asthma & $3(0.2 \%)$ & $4(0.3 \%)$ & $7(0.5 \%)$ \\
\hline DM with acute complications & $6(0.5 \%)$ & $0(0.0 \%)$ & $6(0.5 \%)$ \\
\hline Hypertensive encephalopathy & $2(0.2 \%)$ & $2(0.2 \%)$ & $4(0.3 \%)$ \\
\hline Connective tissue disease & $1(0.1 \%)$ & $2(0.2 \%)$ & $3(0.2 \%)$ \\
\hline ARDS & $2(0.2 \%)$ & $1(0.1 \%)$ & $3(0.2 \%)$ \\
\hline Pneumothorax & $3(0.2 \%)$ & $0(0.0 \%)$ & $3(0.2 \%)$ \\
\hline Malabsorption & $3(0.2 \%)$ & $0(0.0 \%)$ & $3(0.2 \%)$ \\
\hline Aplastic anaemia & $1(0.1 \%)$ & $1(0.1 \%)$ & $2(0.2 \%)$ \\
\hline Anaphylaxis & $2(0.2 \%)$ & $0(0.0 \%)$ & $2(0.2 \%)$ \\
\hline Others & $7(0.5 \%)$ & $6(0.5 \%)$ & $13(1.0 \%)$ \\
\hline Total & $708(54.2 \%)$ & $428(32.8 \%)$ & $1136(87.0 \%)$ \\
\hline \multicolumn{4}{|l|}{ COMMUNICABLE DISEASE } \\
\hline Encephalitis \& meningitis & $36(2.8 \%)$ & $27(2.1 \%)$ & $63(4.8 \%)$ \\
\hline Sepsis & $14(1.1 \%)$ & $13(1.0 \%)$ & $27(2.1 \%)$ \\
\hline TB & $6(0.5 \%)$ & $4(0.3 \%)$ & $10(0.8 \%)$ \\
\hline Pneumonia & $6(0.5 \%)$ & $2(0.2 \%)$ & $8(0.6 \%)$ \\
\hline AWD & $2(0.2 \%)$ & $2(0.2 \%)$ & $4(0.3 \%)$ \\
\hline Enteric fever & $1(0.1 \%)$ & $1(0.1 \%)$ & $2(0.2 \%)$ \\
\hline Leptospirosis & $1(0.1 \%)$ & $0(0.0 \%)$ & $1(0.1 \%)$ \\
\hline Others & $0(0.0 \%)$ & $0(0.0 \%)$ & $0(0.0 \%)$ \\
\hline Total & $66(5.1 \%)$ & $49(3.8 \%)$ & $115(8.8 \%)$ \\
\hline BROUGHT DEAD \&UNDIAGNOSED & $39(3.0 \%)$ & $16(1.2 \%)$ & $55(4.2 \%)$ \\
\hline$\overline{\text { TOTAL }}$ & $813(62.3 \%)$ & $493(37.7 \%)$ & $1306(100.0 \%)$ \\
\hline
\end{tabular}


Undiagnosed \& brought dead cases were 55 (4.2\%). Among the remaining diagnosed 1251 cases, 1136 $(90.8 \%)$ deaths are caused by non communicable diseases and 115 (9.2\%) deaths are caused by communicable diseases. NCD:CD were 9.9:1.

Table-VI

Distribution of major non communicable diseases according to age $(n=1136)$

\begin{tabular}{lccc}
\hline $\begin{array}{l}\text { Age range } \\
\text { (years) }\end{array}$ & NCD (\%) & CVA (\%) & $\begin{array}{c}\text { Poisoning, } \\
\text { drowning, } \\
\text { hanging (\%) }\end{array}$ \\
\hline$<20$ & $52(4.6 \%)$ & $5(0.4 \%)$ & $33(3.0 \%)$ \\
$21-30$ & $68(6.0 \%)$ & $13(1.1 \%)$ & $32(2.8 \%)$ \\
$31-40$ & $80(7.0 \%)$ & $46(4.0 \%)$ & $12(1.1 \%)$ \\
$41-50$ & $194(17.1 \%)$ & $119(10.5 \%)$ & $12(1.1 \%)$ \\
$51-60$ & $277(24.4 \%)$ & $187(16.5 \%)$ & $5(0.4 \%)$ \\
$61-70$ & $262(23.1 \%)$ & $193(17.0 \%)$ & $3(0.3 \%)$ \\
$71-80$ & $135(11.9 \%)$ & $98(8.6 \%)$ & $0(0.0 \%)$ \\
$81-90$ & $55(4.8 \%)$ & $37(3.3 \%)$ & $0(0.0 \%)$ \\
$91-100$ & $11(1.0 \%)$ & $7(0.6 \%)$ & $0(0.0 \%)$ \\
$>100$ & $2(0.2 \%)$ & $1(0.1 \%)$ & $0(0.0 \%)$ \\
& $1136(100 \%)$ & $706(62.1 \%)$ & $97(8.5 \%)$ \\
\hline
\end{tabular}

\section{Discussion:}

Patient safety is the major concern in all health care system. Reviewing the causes of mortality, we can identify the diseases causing significant mortality and any change in the pattern of morbidity and mortality. Mean age at death and mortality rate reflects the economic development of a community and a country. It may also reflect the availability to access to quality health care services. ${ }^{2}$ Mortality rate varied widely from $1.6 \%$ to $25.3 \%$ in different studies in different hospitals and in different countries. ${ }^{1,4,7-11}$ Mortality rate in our study is not higher than most other studies done in similar level hospitals in other countries. In our study group, the average age at death was 56.05 years and most deaths occurred in 41 to 70 age group which is similar to the findings of studies donein other hospitals. ${ }^{2,4,7}$ Though mean age was found lower and lower age group was found to be affected significantly in some hospitals of Karachi, Nigeria where infections caused significant mortality. ${ }^{1,8}$ In our study, below 41 years age, deaths in female were more compared to that of male (Table 1). Mortality rate and deaths was much greater in male sex than female like in a tertiary care hospital in Nigeria. ${ }^{4}$ But in most other studies, male female ratio was almost equal. 1,7,12 In another tertiary level hospital in Nigeria, deaths in female was much higher than male where HIV was the major killer disease. ${ }^{2}$
Mortality varied from month to month in our study (Table-II). Highest mortality was in January which is the coldest month in Bangladesh ${ }^{9}$ and lowest was in September. Higher mortality was during November, December, January and February when it is mild dry winter in Bangladesh ${ }^{9}$. In some studies done in the community with large sample size in countries with marked seasonal change in climate where it was found that cardiovascular deaths increased significantly during winter. ${ }^{13,14}$ It was hypothesized that exposure to winter weather may induce physiologic stress including sympathetic activation, hypercoagulability and infection. ${ }^{13}$ Influenza epidemics, other respiratory infections may also contribute to this variation. ${ }^{14}$ Though climate in Bangladesh is not extreme and there was no influenza epidemic during the study period here, still similar finding was observed in our study supporting significant role of winter weather on mortality caused by cardiovascular disease.

Most deaths occurred during night shift (Table-III) when investigation facilities, specialist consultation, nursing and other manpower were limited. Similar finding was found in another tertiary care hospital in the capital of Bangladesh and also in a study done in Germany. ${ }^{15,16}$ Circadian rhythm of death with more death within $6 \mathrm{AM}$ to $12 \mathrm{PM}$ was mentioned in a study. ${ }^{17}$ As we divided the time of death according to working shift, whether the death pattern followed the circadian rhythm or not was not clear. In our study, we found that most of the death occurred within 24 hours of admission (Table-IV). This is consistent with some studies where both cardiovascular diseases and infections were the major contributor of mortality. ${ }^{2,15}$ Average hospital stay was 42.1 hours which is much lower than that of other studies. ${ }^{2,4,8,18}$ Both the observation may be due to inadequacy of emergency service like absence of ICU facilities in the institute or poor referral system, tendency of general people to get traditional treatment before coming to hospitals causing undue delay in taking treatment.

It had been projected that, by 2020 the prevalence of NCD will parallel that of communicable disease (CD) in developing countries. This is because cardiovascular death is being the leading cause of death in all developing countries and prevalence and death due to infections are decreasing. ${ }^{4}$ This change is due to rapid economic development, improvement of living, nutrition, sanitation, immunization, advent and availability of antimicrobials, change of lifestyle, food habit etc. ${ }^{4}$ In our study we found that among the diagnosed cases, death due to NCD was $90.8 \%$ in compared to $9.2 \%$ of $\mathrm{CD}$ deaths. The difference was very high. It is an institutional ward based study sparing the deaths occurred in other wards of other disciplines and may not reflect the picture of the whole community. Moreover, government is running diverse program to control communicable disease. ${ }^{9}$ Yet, the ratio seems to be very high. It can be explained in 
two ways - either we are treating the CD very well in our hospital or NCD has appeared as a giant killer now a days or both may contribute. Death distribution according to cause (Table-5) shows, death due to cardiovascular events (stroke and IHD) was the leading cause of all deaths contributing $54.1 \%$. So we should give attention to cardiovascular risk factor reduction in community level by smoking cessation, taking healthy diet, increasing physical activity, controlling hypertension and DM. Death due to poisoning, drowning and hanging $(7.4 \%)$ was the next most frequent cause which was almost equal to all CD deaths (8.8\%). It is also alarming and demand intervention for its prevention. Brought dead and undiagnosed deaths were $4.2 \%$ which is not more than the finding of another study done in a tertiary care hospital in the capital of this country. ${ }^{15}$ Stillthis proportion may be reduced by improving the referral system and improving the health care delivery system of the institute. Table 6 shows, $76.5 \%$ of NCD deaths occurred between 41 to 80 years. Among the all NCD deaths, $62.1 \%$ were due to cardiovascular accident (IHD and stroke). Maximum CVA deaths (44\% out of $62.1 \%$ ) were within 41 to 70 years but $5.8 \%$ out of $8.5 \%$ poisoning, drowning $\&$ hanging deaths occurred below 30 years age. We are losing a lot of our young manpower due to poisoning, drowning \& hanging.

\section{Conclusion:}

Deaths due to non communicable diseases are increasing. Stroke and ischemic heart disease are appearing as giant killer even in the developing countries. People should be aware of the means to risk reduction for their prevention.

\section{Conflict of interest: None}

\section{Referrences:}

1. Udonwa NE, Philip-Ephraim EE, GyuseANI, Bassey IE. Mortality Patterns in the Medical Ward of University of Calabar Teaching Hospital, Calabar, Nigeria. Mary Slessor Journal of Medicine 01/2009; 9(2): 19-24.

2. Fadare JO, Afolabi AO. The pattern of medical mortalities in a specialist hospital in north-central Nigeria.Annals of Ibadan Postgraduate Medicine 2010.8(2); 101-5.

3. Wisconsin department of health and family services. Mortality and morbidity in Wisconsin GMS hospitals 1994 - 1995, section 2. Overview of methods. 1994 - 95 report.

4. Chijioke A, Kolo PM. Mortality Pattern at the Adult Medical Wards of a Teaching Hospital in SubSaharan Africa. International Journal of Tropical Medicine, 2009; 4(1): 27-31.

5. Sorinola OO, Weerasinghe C, Brown R. Preventable hospital mortality: learning from retrospective case record review. JRSM 2012 Nov Vol3; 1177.
6. World Health Organigation. Global health observatory (GHO) data. Available at: www.who.int/ gho/ncd/mortality_morbidity/en/

7. Olarinde OJ, Olatunji OY. Pattern of deaths in medical wards of a rurally situated tertiary health institution, Ido Ekiti, Nigeria. Nigerian Journal of Clinical Practice, Mar-Apr 2014, Vol 17; 2: 237-40.

8. Salimuddin A, Areeba E, Syed EA. Mortality pattern in a trust hospital: a hospital based study in Karachi. Journal of Pakistan Medical Association, August, 2013; 63: 1031-5.

9. DGHS, health bulletin 2013: DGHS; 2014: p 54.

10. SB Garko, C.N. Ekweani and C.A. Anyiam. Duration of hospital stay and mortality in the medical wards of Ahmadu Bello University Teaching Hospital, Kaduna. Annals of African medicine 2003;2(2): 68-71

11. Sani MU, Mohammed AZ, Bapp A, Borodo MM. A three-year review of mortality patterns in the medical wards of Aminu Kano Teaching Hospital, Kano, Nigeria. Niger Postgrad Med J. 2007 Dec;14(4):347-51

12. Mortality profile Bangladesh 2011. Health bulletein 2012.

13. Sheth T, Nair C, Muller J, Yusuf S.Increased winter mortality from acute myocadiral infarction and stroke: the effect of age. American College of Cardiology Foundation, 1999; 7:

14. Gemmell I, McLoone P, Boddy FA, Dickinson GJ, Watt GC. Seasonal variation in mortality in Scotland. Int J Epidemiol, 2000; 29(2):274-9.

15. Abedin $\mathrm{MH}$, Hoque MM, Islam ASMS, Chowdhury MFI, Das DC,Begum SA et al. Chronic Liver Disease is One of the Leading Causes of Death in Bangladesh: Experience by Death Audit from a Tertiary Hospital. Euroasian Journal of HepatoGastroenterology,2014; 4(1): 14-7.

16. Docherty J. Moving to Audit: What Every Nurse, Midwife and Health Visitor Needs to Know about Professional Audit: Resource Book. Dundee: Postgraduate Office, Ninewells Hospital and Medical School; 1994: 131.

17. AntônioSérgioCordeiro da Rocha; Mônica Peres de Araújo; Augusta Campos; Rubens Costa Filho; EvandroTinocoMesquita; Marcus Vinicius Santos. Circadian rhythm of hospital deaths: comparison between intensive care unit and non-intensive care unit.Assoc. Med. Bras 2011. vol.57 no.5

18. Hall MJ, Levant S, DeFrances CJ. Trends in Inpatient Hospital Deaths: National Hospital Discharge Survey, 2000-2010. NCHS Data Brief, March 2013; 118: 1-7. 